\title{
Acute effects of unilateral ovariectomy on follicular development in the cyclic hamster*
}

\author{
D. D. Chirast and G. S. Greenwald \\ Departments of Anatomy and Physiology, Ralph L. Smith Research Center, \\ University of Kansas Medical Center, Kansas City, Kansas 66103, U.S.A.
}

\begin{abstract}
Summary. Hamsters were hemispayed at 09:00 h on Day 3 of the cycle (Day 1 = ovulation) and were killed $1 \mathrm{~h}$ after injection of $\left[{ }^{3} \mathrm{H}\right]$ thymidine at 09:00, 12:00, 17:00 or 22:00 h. Unilateral ovariectomy had no effect on the number of Stage 1 or Stage 2 follicles, but there were significantly fewer Stage 3 follicles between 10:00 and 13:00 h. This decrease was not encountered in intact hamsters and was reflected in an increase in the number of Stage 6 (antral) follicles. At 13:00 h there was no difference in the number of atretic follicles between the experimental and control groups. It is concluded that preantral follicles with 6-7 layers of granulosa cells were recruited within $4 \mathrm{~h}$ after unilateral ovariectomy and transformed into antral follicles.
\end{abstract}

\section{Introduction}

Several mammalian species exhibit ovarian compensation after unilateral ovariectomy (Desaive, 1949; Greenwald, 1961; McLaren, 1963; Peppler \& Greenwald, 1970): the ovulation rate of the remaining ovary is doubled, resulting in maintenance of the number of ovulations characteristic of the species. In rats, unilateral ovariectomy results in an increased secretion of FSH (Ramirez \& Sawyer, 1974) which is believed to recruit medium-sized follicles which normally would not develop during the immediate cycle if both ovaries were present (Peppler \& Greenwald, 1970). In the hamster, however, Greenwald (1961) suggested that ovulatory compensation after unilateral ovariectomy was the result of decreased atresia in follicles larger than $267 \mu \mathrm{m}$ ('developing follicles') rather than recruitment of medium-sized follicles, and that these follicles, about 10 per ovary, were present on the day of ovulation and were destined to ovulate or become atretic within the next 4 days.

Because unilateral ovariectomy on Day 3 results in a prompt elevation in serum FSH and LH in the cyclic hamster (Bast, 1975; Bex \& Goldman, 1975; Bast \& Greenwald, 1977), it was of interest to examine the immediate effects of this operation on follicular growth on Day 3 and to identify the follicles involved in compensatory ovulation.

\section{Materials and Methods}

\section{Animal care and treatment}

Virgin golden hamsters (Mesocricetus auratus), weighing $80-120 \mathrm{~g}$, were used after completion of 3 consecutive 4-day oestrous cycles. Cyclicity was assessed by the presence of a conspicuous postovulatory vaginal discharge occurring on the morning of ovulation (Day 1). Pro-oestrus, therefore, corresponds to the afternoon of Day 4. In our colony behavioural oestrus commences at 18:00 h on Day 4 and all hamsters ovulate between 01:00 and 02:00 h on Day 1 (Norman \& Greenwald, 1972). Hamsters were fed lab chow (Purina) and water ad libitum and kept in a $14 \mathrm{~h}$ light (05:00-19:00 h, CST) : $10 \mathrm{~h}$ dark schedule.

Unilateral ovariectomies were performed under light ether anaesthesia via a lumbar approach at 09:00 $\mathrm{h} \pm 15$ min on Day 3 in 16 hamsters. Sham operations were carried out in the 16 control hamsters.

* Reprint requests to Dr G. S. Greenwald.

† Present address: Division of Natural and Physical Sciences, University of Colorado at Denver, 1100 Fourteenth Street, Denver, Colorado 80202, U.S.A. 
Single, intraperitoneal injections of $100 \mu \mathrm{Ci}\left[{ }^{3} \mathrm{H}\right]$ thymidine (sp. act. $15 \cdot 7 \mathrm{Ci} / \mathrm{mmol}$ : AmershamSearle) were given to all hamsters at $09: 00,12: 00,17: 00$ or 22:00 h on Day 3. The 4 hamsters of each type in each group were killed by ether anaesthesia $1 \mathrm{~h}$ after the thymidine injection.

\section{Autoradiographic procedure}

Ovaries were removed, fixed in Bouin's fixative for at least $24 \mathrm{~h}$, dehydrated in ethanol and embedded in paraffin wax. Ovaries were sectioned serially at $7 \mu \mathrm{m}$ and sections were mounted on acidcleaned slides. Slides were then hydrated and dipped in Kodak NTB-3 emulsion in a dark room under a red safelight. After coating, slides were dried in the vertical position for at least $30 \mathrm{~min}$ and then stored in light-tight slide boxes for $5 \frac{1}{2}$ weeks at $5^{\circ} \mathrm{C}$. After exposure, slides were developed in Dektol developer $\left(20^{\circ} \mathrm{C}\right)$ and stained with haematoxylin and eosin.

\section{Follicle classification and counting procedure}

Follicles were counted in every fifth section at $\times 100$ magnification according to the following classification (Greenwald, 1974): Stage 1: preantral follicles with 2-3 layers of granulosa cells surrounding the oocyte; Stage 2: preantral follicles with 4-5 layers of granulosa cells; Stage 3: preantral follicles with 6-7 layers of granulosa cells; Stage 4: preantral follicles with 8 or more complete layers of granulosa cells; Stage 5: follicles with early signs of antral cavity formation, i.e. small, clear lacunae amongst the granulosa cells; Stage 6: antral follicles characterized by large, well formed antral cavities.

Only normal, non-atretic follicles with visible nucleoli in their oocytes were included in the follicle counts, and the number of follicles obtained represented the total number per ovary and not a relative value. The results were expressed as the mean ( \pm s.e.m.) number of follicles for each stage per ovary. The averages for each time interval were based on 4 ovaries from 4 different hamsters. The mean ( \pm s.e.m.) number of labelled follicles per ovary was also determined. A labelled follicle was one which had 5 or more labelled granulosa cells in the cross-section containing the nucleus and nucleolus and a labelled granulosa cell was one with 5 or more silver grains above the nucleus. Since the background label was insignificant it was unnecessary to correct for it in determining the number of labelled cells.

Atretic follicles greater than $267 \mu \mathrm{m}$ in diameter were counted in every fifth section in the ovaries from sham-operated and unilaterally ovariectomized hamsters killed at 13:00 h. All follicles showing any signs of atresia (pyknotic nuclei in the granulosa cells) were counted.

The diameter of 10 randomly selected Stage-6 follicles/group was determined with an ocular micrometer by calculating the average of two perpendicular measurements taken at the limit of the membrana granulosa across the largest cross-section of the follicle. To correlate stage of follicular development with follicular diameter, 4 ovaries were examined from control hamsters killed at 15:00 h on Day 3 of the cycle and the diameters of 5 follicles from each ovary were determined for each stage of follicular development (Stages 1-6).

Statistical analysis of the data was made with Student's $t$ test and a level of $P<0.05$ was taken as significant.

\section{Results}

On Day 3 of the oestrous cycle, follicles were never encountered in Stage 4 and only rarely in Stage 5 in the experimental and control hamsters (Table 1). Unilateral ovariectomy did not affect the number or percentage of labelled Stage 1 and 2 follicles. The number of Stage 3 follicles was similar in both groups of hamsters except at 13:00 h. The reduced number of Stage 3 follicles at 13:00 h in the experimental animals was reflected in a statistically significant increase $(P<0.05)$ in numbers of Stage 6 (antral) follicles (Table 1). The diameters of Stage 6 follicles in the two groups did not differ until 23:00 $\mathrm{h}$ when they were $521 \pm 9$ (s.e.m.) and $483 \pm 13 \mu \mathrm{m}$ in the unilaterally ovariectomized and shamoperated hamsters, respectively. Histologically, Stage 6 follicles were similar at 10:00 and 13:00 h. 


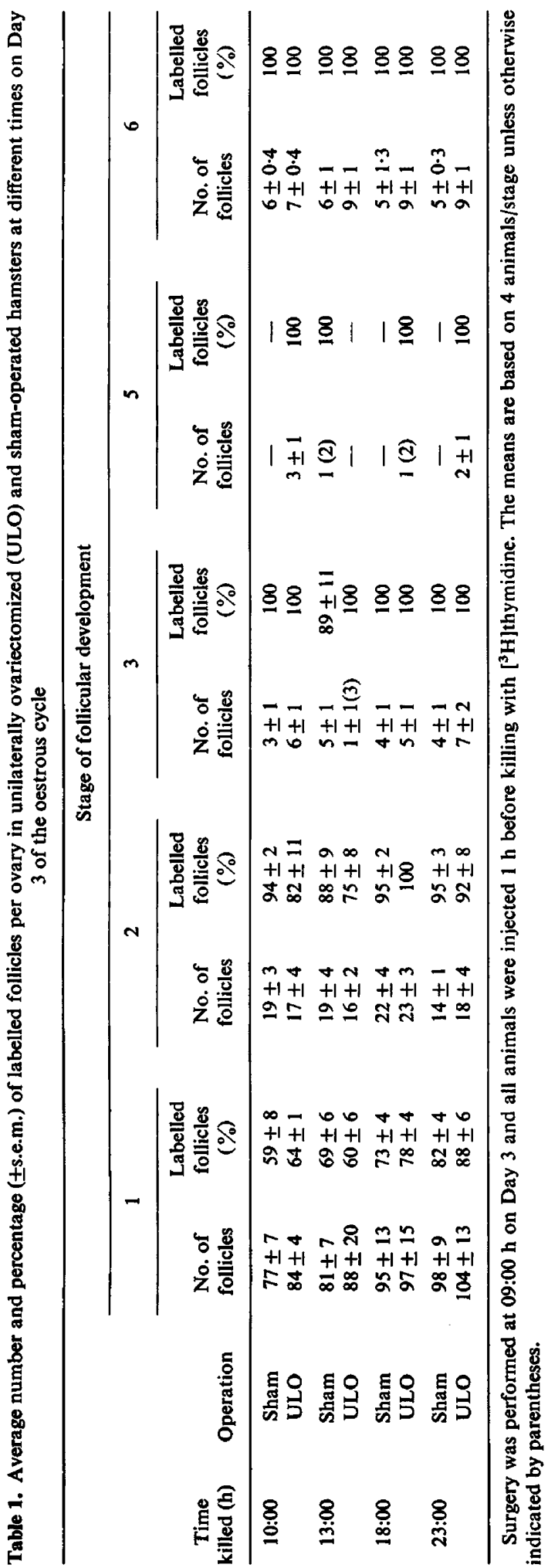


However, at later times, thecal development was slightly enhanced in the experimental hamsters. Despite differences in size and thecal development, there were no differences in thymidine labelling in Stage 6 follicles throughout the experimental period. The number of atretic follicles $(>267 \mu \mathrm{m})$ in ovaries from sham-operated and unilaterally ovariectomized hamsters killed at 13;00 $\mathrm{h}$ was not significantly different $(12 \cdot 3 \pm 4 \cdot 1$ and $14 \cdot 3 \pm 2 \cdot 0$ /ovary, respectively).

\section{Discussion}

Within $4 \mathrm{~h}$ after unilateral ovariectomy of hamsters on Day 3, the remaining ovary shows accelerated growth of preantral follicles with 6-7 layers of granulosa cells (Stage 3) into antral follicles (Stage 6). This rapid follicular response appears to be the basis for compensatory ovulation in the acutely unilaterally ovariectomized cyclic hamster. Normally, 4-8 days are required for Stage 3 follicles to mature into antral follicles (Chiras \& Greenwald, 1977).

The rapid recruitment of medium-sized follicles in the hamster after hemispaying on Day 3 is paralleled by an equally abrupt increase in serum gonadotrophins (Bast \& Greenwald, 1977). By $4 \mathrm{~h}$ after this operation, serum FSH is significantly increased over control values and the elevated levels are maintained for at least $12 \mathrm{~h}$ (Bast $\&$ Greenwald, 1977). There is also a significant increase in serum LH which is even more transitory than the elevation in FSH, with the levels subsiding to control values by 20:00 h when operation is at $12: 00 \mathrm{~h}$ on Day 3 (Bast \& Greenwald, 1977). It is therefore impossible at this point to assign a primary role to $\mathrm{FSH}$ or $\mathrm{LH}$ as the hormone initiating the rapid growth of Stage 3 follicles since both hormones may be necessary.

However, experiments in vitro demonstrate that FSH affects more classes of follicles than LH and that LH needs more time to exert its effects (Ryle, 1972). Similarly, $\left[{ }^{3} \mathrm{H}\right]$ thymidine uptake is increased in the mouse ovary as early as 15 min after intravenous injection of FSH (Eshkol, Hardy \& ParienteCoriat, 1970), whereas LH reduces the absolute amount of $\left[{ }^{14} \mathrm{C}\right]$ thymidine uptake by the mouse ovary in vitro (How, Chaplin \& Ryle, 1970). We have previously demonstrated equally rapid mobilization of follicles after administration of PMSG or FSH to hypophysectomized (Moore \& Greenwald, 1974; Chiras, 1976) or intact hamsters (Chiras, 1976).

The present finding contradicts the results of a previous study (Greenwald, 1961) in which follicles were classified on the basis of their diameter $24 \mathrm{~h}$ after unilateral ovariectomy and only follicles larger than $267 \mu \mathrm{m}$ were assessed. Since on Day 4 there were fewer follicles greater than $267 \mu \mathrm{m}$ in untreated, cyclic hamsters than in unilaterally ovariectomized hamsters, it was concluded that hemispaying resulted in reduced follicular atresia (Greenwald, 1961). In the present study it is probable that the larger number of follicles greater than $267 \mu \mathrm{m}$ in the experimental hamsters was due to the precipitous transformation of Stage 3 follicles into antral follicles. This appears to be the result of decreased atresia when the number of smaller follicles $(<267 \mu \mathrm{m})$ or atretic follicles is not determined. However, in the present study, the number of large atretic follicles was the same in control and experimental hamsters, supporting the contention that unilateral ovariectomy results in rapid follicular recruitment rather than any change in atresia.

Table 2. Correlation of stages of follicular development and follicular diameter at 15:00 h on Day 3 of the cycle in hamsters

\begin{tabular}{cccc}
\hline $\begin{array}{c}\text { Stage of } \\
\text { follicular } \\
\text { development }\end{array}$ & No. & Mean \pm s.e.m. & Range \\
\cline { 2 - 4 } & 20 & $136 \pm 3$ & $113-167$ \\
1 & 20 & $171 \pm 3$ & $146-193$ \\
3 & 20 & $196 \pm 2$ & $180-220$ \\
4 & 20 & $252 \pm 6$ & $213-300$ \\
5 & 5 & $332 \pm 16$ & $293-360$ \\
6 & 20 & $427 \pm 7$ & $367-513$ \\
\hline
\end{tabular}


In an effort to reconcile these differences, follicular diameter was correlated with the currently used classification which is based on the number of granulosa layers present (Greenwald, 1974). The results in Table 2 indicate that follicles in Stage 4 and above were probably the ones assessed in the earlier study (Greenwald, 1961). These results therefore support the suggestion that recruitment of follicles is more important than reduced follicular atresia as the primary ovarian response to the acute effects of hemispaying in the hamster as well as in the rabbit (Desaive, 1949), guinea-pig (Hermreck \& Greenwald, 1964) and rat (Peppler \& Greenwald, 1970).

D.C. acknowledges the financial support of training grants from NICHD (5T01 HD0025) and from the Ford Foundation. The research was supported by grants from NIH (HD 00596) and the Ford Foundation.

\section{References}

BAST, J.D. (1975) Cyclic elevation in serum levels of follicle-stimulating hormone (FSH) following unilateral ovariectomy of the hamster. Anat. Rec. 181, 308, Abstr.

Bast, J.D. \& Greenwald, G.S. (1977) Acute and chronic elevations in serum levels of FSH after unilateral ovariectomy in the cyclic hamster. Endocrinology 100, 955-966.

Bex, F.J. \& Goldman, B.D. (1975) Serum gonadotrophins and follicular development in the Syrian hamster. Endocrinology 96, 928-933.

CHIRAS, D.D. (1976) Studies on ovarian follicular kinetics and thymidine incorporation in the golden hamster, Mesocricetus auratus. Ph.D. thesis, University of Kansas.

Chiras, D.D. \& Greenwald, G.S. (1977) An autoradiographic study of long-term follicular development in the cyclic hamster. Anat. Rec. 184, 331-337.

Desaive, P. (1949) Etude des processus compensateurs de l'appareil folliculaire dans l'ovaire de lapine adulte. Archs Biol. 60, 137-205.

Esh kol, A., Hardy, B. \& Pariente-Coriat, C. (1970) Changes in the rate of nucleic acid and protein synthesis in the juvenile mouse ovaries after FSH stimulation. In Gonadotrophins and Ovarian Development, pp. 292-300. Eds W. R. Butt, A. C. Crooke and M. Ryle. Livingstone, Edinburgh.

GREENWALD, G.S. (1961) Quantitative study of follicular development in the ovary of the intact or unilaterally ovariectomized hamster. J. Reprod. Fert. 2, 351-361.
Greenwald, G.S. (1974) Quantitative aspects of follicular development in the untreated and PMStreated cyclic hamster. Anat. Rec. 178, 139-144.

Hermreck, A.S. \& Greenwald, G.S. (1964) The effects of unilateral ovariectomy on follicular maturation in the guinea pig. Anat, Rec. 148, 171-176.

How, M.J., Chaplin, M.F. \& RYLE, M. (1970) The distribution of $\left[{ }^{14} \mathrm{C}\right]$-thymidine in mouse ovaries cultured in vitro with and without gonadotrophic hormones. Acta biochim. Biophys. 213, 226-228.

McLaren, A. (1963) Mechanism of ovarian compensation following unilateral ovariectomy in mice. $J$. Reprod. Fert. 6, 321-322.

MOORE, P.J. \& GREENWALD, G.S. (1974) Effect of hypophysectomy and gonadotrophin treatment on follicular development and ovulation in the hamster. Am. J. Anat. 139, 37-48.

NoRman, R.L. \& GReEnwald, G.S. (1972) Follicular histology and physiological correlates in the preovulatory hamster. Anat. Rec. 173, 95-108.

Peppler, R.D. \& Greenwald, G.S. (1970) Effects of unilateral ovariectomy on ovulation and cycle length in 4- and 5-day cycling rats. Am. J. Anat. 127, 1-8.

RamiRez, V.D. \& SAWYer, C.H. (1974) A sex difference in the rat pituitary FSH response to unilateral gonadectomy in plasma radioimmunoassays. Endocrinology 94, 475-482.

RYLE, M. (1972) The growth in vitro of mouse ovarian follicles of different sizes in response to purified gonadotrophins. J. Reprod. Fert. 30, 395-405.

Received 23 May 1977 